\title{
O DIREITO DE ACRESCER EM RELAÇÃO AO LEGADO DE DINHEIRO
}

\author{
THE RIGHT TO ADD IN ITS CONCERN WITH THE LEGACY OF \\ MONEY
}

\author{
${ }^{1}$ Raphael Rego Borges Ribeiro \\ ${ }^{2}$ João Glicério de Oliveira Filho
}

\section{RESUMO}

O presente artigo trata do direito de acrescer em relação ao legado de dinheiro no ordenamento jurídico brasileiro. Adota-se o método hipotético-dedutivo, fundamentado em lições doutrinárias do Direito Civil. A hipótese testada é a de que a qualidade fungível do dinheiro seria incompatível com o exercício direito de acrescer pelos colegatários. Inicialmente, são introduzidas noções basilares acerca da sucessão testamentária a título singular e do legado de dinheiro. Em seguida, aprofunda-se no estudo do direito de acrescer, analisando seus fundamentos, seu regime jurídico e seus efeitos. Finalmente, é diretamente enfrentada a pertinência da hipótese traçada, concluindo-se por sua parcial confirmação.

Palavras-chave: Legado de dinheiro, Legado de dinheiro, Testamento, Sucessão a título singular

\begin{abstract}
This paper discusses the right to add in its concern with the legacy of money, regarding the Brazilian legal system. It is applied a hypothetical-deductive method, grounded on doctrinal lessons of Civil Law. It is tested the hypothesis that the fungible aspect of money is not consistent with the others legatees' right to add. At a first moment, basic notions about individual succession and legacy of money. Further, the paper deepens in the study of the right to add, examining its foundations, its legal framework and its effects. Finally, the outlined hypothesis is directly faced, leading to its partial confirmation.
\end{abstract}

Keywords: Legacy of money, Right to add, Will, Individual succession

\footnotetext{
${ }^{1}$ Mestre em Direito na Universidade Federal da Bahia - UFBA, Bahia, BA, (Brasil). Professsor da Universidade Federal da Bahia - UFBA, Bahia, BA(Brasil). E-mail: raphaelregobr@gmail.com.

${ }^{2}$ Pós-Doutor pela Universidade de Lisboa, UL, Lisboa, Portugal. Professor da professor de Direito Comercial na Faculdade de Direito da Universidade Federal da Bahia - UFBA, Salvador, BA.(Brasil) E-mail: joao@joaoglicerio.com.
} 


\section{INTRODUÇÃO}

A presente investigação busca enfrentar o questionamento a respeito da possibilidade de aplicação do direito de acrescer a uma modalidade específica de sucessão a título singular: o legado de dinheiro. A hipótese a ser trabalhada é de que os mencionados institutos jurídicos são inconciliáveis, notadamente em decorrência do caráter fungível do dinheiro.

A fungibilidade do dinheiro, objeto do legado no caso analisado, seria incompatível com a previsão normativa expressa de que o ius accrescendi entre colegatários se opera exclusivamente a respeito de coisas infungíveis ou que não possam ser divididas sem risco de desvalorização.

Para o desenvolvimento da pesquisa, deve-se inicialmente compreender o legado enquanto figura jurídica típica da sucessão testamentária. Para este mister, faz-se necessário expor conceitos elementares a respeito do testamento enquanto negócio jurídico de manifestação de última vontade.

$\mathrm{Na}$ sequência, aprofundar-se-á acerca do dinheiro enquanto conteúdo de legado. Demonstra-se igualmente imprescindível uma análise acerca do ius accrescendi, dando ênfase ao seu fundamento jurídico e às normas que atualmente o regulamentam no direito brasileiro.

Por fim, observando o regime jurídico de ambos os institutos, verificar-se-á se a hipótese pode ser confirmada.

\section{O LEGADO DE DINHEIRO}

A análise da possibilidade de exercício do direito de acrescer entre beneficiários de legado de dinheiro torna imprescindível prévia compreensão do conteúdo de tal disposição testamentária. No direito brasileiro, apenas pode haver legado instituído por meio de testamento, razão pela qual faz-se necessário, ainda, o aprofundamento acerca da sucessão causa mortis que se opera orientada pela manifestação de última vontade.

\subsection{A SUCESSÃO TESTAMENTÁRIA}

Juridicamente, o sentido amplo concedido ao termo "sucessão" refere-se às situações em que "um direito muda de titular, sem que a relação jurídica sofra uma transformação" (DANTAS, 1991, p.443). A mudança de titularidade nestes termos pode resultar de ato entre 
vivos, bem como da morte de pessoa física. No entanto, apenas esta última - a sucessão causa mortis - é objeto do Direito das Sucessões (RIBEIRO, 2015, p.482).

O livro do Direito das Sucessões é o último da Parte Especial da Lei 10.406/2002, antencedendo apenas às Disposições Finais e Transitórias do referido diploma. Observando esta circunstância, Giselda Hironaka (2014, p.20) sustenta que, "assim como a vida termina com a morte, o Código Civil também termina com ela, e este é, sem dúvida, um lembrete para o quanto o Código Civil é um belíssimo retrato da vida dos particulares”.

De acordo com as normas do direito sucessório, exige-se que o pretenso sucessor seja chamado à sucessão do falecido, o que se opera através de um título jurídico. Este título, ensina Lacerda de Almeida (1915, p.58), será testamentário (a vontade do defunto solenemente manifestada) ou legítimo (constituído por força de lei, suprindo ou mesmo restringindo a vontade do falecido). No direito brasileiro, nada impede que a sucessão seja ao mesmo tempo regida por testamento e por disposição legal ${ }^{1}$.

Conforme já ressaltado, interessa à presente pesquisa de forma específica a sucessão testamentária. Para tanto, necessário se faz compreender o que é o testamento. A origem etimológica da palavra é esclarecida por Euclides de Oliveira (2006, p.912):

Testamentum, em latim, significa declaração de última vontade. A palavra apresenta variações diversas como testamen, para testemunho e testis, para testemunha, ou seja, aquele que atesta. Nas línguas românicas segue-se a mesma denominação: testamento, em espanhol e italiano, testament, em francês, também testament, em inglês, mas neste com o substitutivo menos formal da expressão will, no sentido de vontade (last will - última vontade).

Para Silvio Venosa (2011, p.180), testamento é o "invólucro que tem em mira validamente proteger a vontade do morto". Trata-se de ato de última vontade que pode conter

\footnotetext{
${ }^{1}$ Em alguns casos, porém, a liberdade de testar é limitada por normas de ordem pública, a exemplo das regras de capacidade testamentária, de proteção à legítima dos herdeiros necessários, entre outras, assuntos que fogem à temática do presente trabalho.
} 
disposições patrimoniais e providências de caráter pessoal e familiar, que serão executadas após a morte do testador (MAXIMILIANO, 1952, p.331).

O testamento é um negócio jurídico, eis que se trata de manifestação de vontade destinada a produzir efeitos jurídicos. Orosimbo Nonato (1957, v.I., p.102) realça as características do testamento, como sendo ato jurídico de última vontade (causa mortis) a título gratuito, solene, essencialmente revogável, unilateral e personalíssimo.

Por fim, deve ser destacado o posicionamento de Zeno Veloso (2004, p.118), para quem a sucessão testamentária "não é, exatamente, como alguns dizem, a vontade de um morto que se vai cumprir". De acordo com o mencionado autor, na medida em que mortos não têm vontade, o testamento constitui "vontade de um vivo, para depois da morte", visto que "a vontade foi do vivo; os efeitos ocorrem com o falecimento dele".

\subsection{A SUCESSÃO A TÍTULO SINGULAR}

Já se expôs que a sucessão causa mortis é a substituição de uma pessoa por outra nas relações jurídicas transmissíveis deixadas por aquela, em razão de seu falecimento. Este fenômeno pode ser operado a título universal ou a título singular.

Na sucessão a título universal, o falecido transmite a totalidade ou uma parte ideal do patrimônio que tinha em vida. Neste caso, há transferência da herança, e por essa razão o sucessor recebe o epíteto de herdeiro. Esta modalidade sucessória pode ser operada tanto em decorrência da lei quanto em virtude de disposição testamentária.

Em contrapartida, em se tratando de sucessão a título singular, o sucedido transfere para o sucessor bem certo e determinado (ou determinável). Trata-se do legado, cujo beneficiado é chamado de legatário. Para Itabaiana de Oliveira (1952, p.529), "legado é a porção certa e determinada da herança deixada pelo testador a alguém, por título singular”.

No direito brasileiro, o legado é um instituto exclusivo da sucessão testamentária. Assim, constará no testamento tanto a indicação a respeito de quem será legatário, como a especificação do bem ou da prestação que consistirá no objeto do legado.

Enquanto ato jurídico negocial, o testamento está subordinado às regras de validade dos negócios jurídicos previstas na Parte Geral do Código Civil. Dessa forma, o objeto do legado deve ser lícito, possível e determinado ou, ao menos, determinável. Respeitados tais requisitos, o testador tem ampla liberdade de disposição. 
A doutrina tradicionalmente se posiciona no sentido de que o objeto do legado deve ter conteúdo patrimonial. De acordo com Luiz da Cunha Gonçalves (1962, p.64), "pode ser objecto de legado tudo o que tenha valor pecuniário, directa ou indirectamente, um direito, ou um facto, tudo o que pode ser objecto das obrigações e transmitido a outrem".

Por outro lado, Pontes de Miranda (2005, p.432) sustenta que não é de mister que efetivamente exista expressão econômica no legado. Seu objeto, entende o renomado civilista, pode possuir "valor religioso, moral, artístico, político, independente do valor venal que é puramente de ordem econômica". O mencionado doutrinador complementa seu raciocínio exemplificando que podem ser legadas fotografias e cartas com mero significado sentimental para os interessados.

\subsection{O DINHEIRO ENQUANTO OBJETO DE LEGADO}

O Código Civil apresenta um rol exemplificativo de bens que podem ser transmitidos a título singular legados. Nos termos da codificação civilista, o legado pode ter por objeto um crédito, a quitação de uma dívida, a prestação de alimentos, prestações periódicas, o direito de usufruto e, finalmente, uma soma em dinheiro.

A conceituação do legado de dinheiro não é de difícil compreensão: o testador beneficia o legatário com importância pecuniária determinada. Quando transmitido por mrio de legado, o montante pecuniário não é definido a partir de uma fração ideal do espólio, mas através de diretrizes específicas do testador.

A lei brasileira não faz referência direta à necessidade de o benefício ser necessariamente expresso em moeda nacional. Entretanto, o Decreto-lei 857/1969 prevê a nulidade de contratos, títulos e quaisquer documentos, bem como das obrigações que, exequíveis no Brasil, estipulem pagamento em ouro ou em moeda estrangeira. As exceções elencadas no art. $2^{\circ}$ do mencionado diploma normativo não incluem o testamento.

Ocorre que, bem como outras previsões normativas que vedam negócios realizados em moeda estrangeira, o referido Decreto-Lei deve ser aplicado em conformidade com o princípio da liberdade de testar. O ordenamento jurídico brasileiro confere uma ampla margem de autonomia privada no exercício das manifestações de última vontade. 
No mais, em se tratando o legado de uma liberalidade cujo conteúdo é definido de forma unilateral e personalíssima pelo testador, a nulidade da cláusula testamentária que prevê legado em moeda estrangeira seria desproporcionalmente grave em relação aos interesses que se buscam proteger com a proibição da obrigação valutária. Prevalece, portanto, a validade de cláusula testamentária prevendo legado em moeda estrangeira, desde que o referido pagamento, caso operado em território nacional, seja feito pelo equivalente em Real.

Independente da referência monetária adotada pelo testador, é imprescindível que o montante pecuniário seja determinado ou determinável. Neste sentido, entende Carlos Maximiliano (1964, p.375) que a disposição testamentária deve conter ao menos uma das seguintes orientações: indicação da quantidade, especificação da qualidade ou designação do lugar em que encontra o legado.

Havendo indicação apenas em relação à quantidade de dinheiro, o legado implicará no pagamento do valor nominal da deixa testamentária. A título exemplificativo, constituiria legado de dinheiro o implemento de cláusula testamentária com conteúdo semelhante a "deixo a $A$ vinte mil reais".

Por outro lado, na eventualidade de o de cujus especificar a qualidade do montante pecuniário, entende-se que ele pretendeu "fixar o quantum, pagável em papel nacional correspondente" (MAXIMILIANO, 1964, p.376). A título exemplificativo, imagine-se um benefício com termos similares a "instituo $B$ meu legatário da quantia de vinte mil reais em ouro". Neste caso, em vez de pagamento pelo valor nominal previsto no testamento, a entrega do legado será feita através da cotação ${ }^{2}$ fixada pelo testador, equivalente em moeda nacional.

Há ainda a possibilidade de o testador ter designado o lugar onde deve ser encontrada a quantia em dinheiro. Trata-se, exemplificativamente, de cláusula testamentária equivalente a "lego a $C$ vinte mil reais que se encontram no cofre de minha residência". Neste caso, "entrega-se o que existe no lugar indicado; se falta um pouco, ou tudo, o legatário perde; se algo sobra, o excesso pertence aos herdeiros” (MAXIMILIANO, 1964, p.376).

Por fim, importante destacar que o dinheiro é bem caracterizado pela fungibilidade. Bens fungíveis são aqueles que podem se substituir por outros da mesma espécie, qualidade e

\footnotetext{
${ }^{2}$ Cotação esta que pode ser em ouro, dólar, euros, libras esterlinas, entre outros ativos financeiros. quantidade. Em outras palavras, "são substituíveis porque são idênticos, econômica, social e juridicamente" (AMARAL, 2008, p.360).
} 
De acordo com Francisco Amaral (2008, p.361), "as notas de dinheiro são individualizadas pelo número, todavia são fungíveis, pois o que interessa é o seu valor, que independe da numeração". Para o referido autor, a fungibilidade da moeda decorre de uma necessidade prática, na medida em que seria inviável se exigir a devolução das mesmas notas ou moedas no exemplo de um empréstimo de dinheiro.

\section{O DIREITO DE ACRESCER}

O direito de acrescer encontra-se regulado no Capítulo VIII do Título III do Livro do Direito das Sucessões do Código Civil de 2002. Trata-se de instituto típico da sucessão que se opera por força de testamento ${ }^{3}$, sendo aplicado tanto em benefício de herdeiros testamentários quanto de legatários. Constitui tema notadamente sensível para a doutrina, sendo inclusive reputada "a matéria mais sutil e mais espinhosa do direito romano" (PONTES DE MIRANDA, 2005, p.662).

Conforme leciona Carlos Maximiliano (1964, p.460), é verificado o direito de acrescer "quando, favorecidos com uma só liberalidade vários herdeiros, ou legatários, a cota de um destes beneficiados em conjunto que não quer, ou não pode, receber, aumenta a dos outros". Pontes de Miranda (2005, p.662), em idêntico sentido, aduz que o ius accrescendi se opera tanto na sucessão a título universal quanto na sucessão a título singular nas situações em que, "chamadas algumas pessoas a recolher, concorrentemente, e a partilhar entre si, coisas ou direitos, quer a lei que, se uma delas falta, as outras obtenham como se não houvesse existido a que faltou".

Alguns autores expõem que, em vez de haver direito de acrescer, existe na verdade um direito de não decrescer - iure non decrescendi. De acordo com tal posicionamento, "aos

\footnotetext{
${ }^{3}$ Reconhece-se, todavia, a existência de ius accrescendi no direito das coisas (quanto ao usufruto constituído em favor de duas ou mais pessoas, se por estipulação expressa o quinhão da que falecer couber aos sobreviventes), assim como no direito das obrigações (por exemplo, quanto à constituição de renda, é possível que, morto um dos beneficiários, os demais recolham a parte do que morreu, desde que haja previsão no respectivo ato). Também pode se falar excepcionalmente em direito de acrescer na sucessão legítima na hipótese de renúncia - quando o quinhão que competiria ao renunciante competirá aos coerdeiros da mesma classe que aquele ocupava; inclusive por essa razão
} 
herdeiros, ou legatários, em conjunto e a cada um de per si, cabia o todo; se um não recolhe a sua parte, não diminui a herança ou legado; subdivide-se entre os demais" (MAXIMILIANO, 1964, p.460). É neste sentido que se manifesta também Pontes de Miranda.

Nas fontes romanas, está accrescere, mas a expressão não traduz bem o que se passava: parece que a parte do que faltou acresce, isto é, aumenta, se soma a que desde o início fora conferida ao herdeiro, ou legatário. E não é isto o que se dá: o que aumenta - só pelo pressuposto de que o que faltou não faltaria em verdade aumentou, acresceu; porque, rigorosamente, a força de receber é a mesma, originária, e não resultante. (PONTES DE MIRANDA, 2005, p.663)

Silvio Venosa (2011, p.291) aduz que, em verdade, o direito de não decrescer se refere à circunstância de que "o herdeiro ou legatário não poderia exercer sozinho o direito, porque deveria compartilhá-lo com outro sucessor, que tinha o mesmo direito”. Quando este outro sucessor desaparece, "o remanescente sobrevivo passa a ter o direito de forma integral". O mencionado doutrinador conclui afirmando que a distinção entre ius accrescendi e iure non decrescendi é sutil demais para que se lhe dê importância.

\subsection{FUNDAMENTO DO DIREITO DE ACRESCER}

No direito brasileiro, já não prevalece o brocardo latino nemo pro parte testatus pro parte intestatus, decedere potest ${ }^{4}$. Pelo contrário, a sucessão legítima pode concorrer com a testamentária, desde que nesta última sejam respeitadas as normas de ordem pública limitadoras da capacidade e da liberdade de testar. Partindo desta premissa, os autores buscam explicar o fundamento hodierno do direito de acrescer.

Há posicionamento doutrinário no sentido de que o fundamento lógico do mencionado fenômeno é a manutenção da "integralidade da herança, da quota hereditária ou da coisa ou coisas legadas em relação aos diversos sujeitos simultaneamente chamados; donde é lógico resultar a devolução da porção do deficiente ao todo donde saiu" (LACERDA DE ALMEIDA, 1915, p.151). Ocorre que, com a devida vênia, esta corrente não deve prosperar.

\footnotetext{
${ }^{4}$ Princípio do Direito Romano segundo o qual ninguém poderia morrer parte testado, parte intestado.
} 
Silvio Rodrigues (2003, p.223) aduz que "não está provado que o fracionamento da propriedade, por força da sucessão hereditária, represente um inconveniente; aliás, se o fosse, seria o caso de se restabelecerem os direitos de primogenitura e varonia". O referido doutrinador argumenta ainda que o direito de acrescer, por si só, seria incapaz de evitar que a propriedade seja fracionada.

Por essa razão, prepondera na doutrina a opinião de que o fundamento atual do ius accrescendi é a vontade presumida do testador. Nesse sentido, Itabaiana de Oliveira (1952, p.504) aduz que "o direito de acrescer tem por fundamento básico a vontade presumida do testador". Do mesmo modo se manifestam Silvio Venosa (2011, p.292), Carlos Maximiliano (1964, p.465) e Carlos Roberto Gonçalves (2013, p.393). Por sua perfeição técnica, cita-se o magistério de Arnaldo Rizzardo:

Parece que se embasa o direito de acrescer na vontade presumida do testador em contemplar as pessoas especificadas no seu ato de última vontade, de modo que, na impossibilidade de uma delas, por circunstâncias alheias a ele, perdurar na designação feita, vá o que lhe cabia aos demais escolhidos. Se pretendesse a transmissão aos herdeiros da pessoa afastada, por evidente que os referiria. Assim, nota-se que o fundamento básico do direito de acrescer está em respeitar a vontade do testador, ou em obedecer seu presumível intento, que é o de recolher, pelo coerdeiro, ou colegatário, a parte que não recebeu aquele que ou morreu, ou renunciou, ou caiu em indignidade por sua conduta. (RIZZARDO, 2011, p.450)

Fundamentado o direito de acrescer no querer presumido do testador, a vontade expressa deste deverá sempre prevalecer. Assim, diz-se que as normas a este respeito são meramente supletivas, sendo "facultado ao estipulante outorgar o ius accrescendi em hipóteses imprevistas na lei e negá-lo em situações nela abrangidas” (NONATO, 1957, p.229).

Semelhante a orientação de Carlos Maximiliano (1964, p.466), para quem "pode o estipulante conferir, em casos não alcançados pelo Código Civil, o direito de acrescer, e determinar o contrário, exclui-lo em hipóteses em que a lei o admite". Compartilha deste entendimento Pontes de Miranda (2005, p.677), entendendo que os preceitos da lei a respeito 
do ius accrescendi "só se aplicam quando a voluntas testatoris não se manifestou em contrário".

\subsection{REGIME JURÍDICO DO DIREITO DE ACRESCER}

De acordo com o quanto já exposto, o ius accrescendi constitui direito dos sucessores testamentários, tanto a título universal quanto a título singular. O Código Civil brasileiro em vigor dispõe sobre o direito de acrescer entre coerdeiros em seu artigo 1.941:

Art. 1.941. Quando vários herdeiros, pela mesma disposição testamentária, forem conjuntamente chamados à herança em quinhões não determinados, $\mathrm{e}$ qualquer deles não puder ou não quiser aceitá-la, a sua parte acrescerá à dos co-herdeiros, salvo o direito do substituto (sic).

O mesmo diploma normativo estabelece o ius accrescendi entre colegatários no seu artigo 1.942, prevendo que “o direito de acrescer competirá aos co-legatários, quando nomeados conjuntamente a respeito de uma só coisa, determinada e certa, ou quando o objeto do legado não puder ser dividido sem risco de desvalorização". Na sequência, o Código Civil de 2002 estabelece que o direito de acrescer é verificado quando ocorre a falta de um dos coerdeiros ou colegatários ${ }^{5}$ :

Art. 1.943. Se um dos co-herdeiros ou co-legatários, nas condições do artigo antecedente, morrer antes do testador; se renunciar a herança ou legado, ou destes for excluído, e, se a condição sob a qual foi instituído não se verificar, acrescerá o seu quinhão, salvo o direito do substituto, à parte dos coherdeiros ou co-legatários conjuntos (sic).

Verifica-se que, em qualquer caso, faz-se imprescindível a verificação concomitante de duas condições para a configuração do ius acrescendi: em primeiro lugar, os herdeiros ou os legatários devem ter sido nomeados em disposição conjunta sobre os mesmos bens ou a

\footnotetext{
${ }^{5}$ De acordo com Antonio Pereira (2013), o Novo Acordo Ortográfico entre países de língua portuguesa prevê que, nas formações com prefixos e em formações por recomposição, emprega-se o hífen quando o segundo elemento começar com a letra "h". Seria o caso de "co-herdeiro", grafia inclusive adotada atualmente por Portugal. Ocorre que a Academia Brasileira de Letras (ABL), com base no "princípio da simplificação", decidiu que sempre haverá aglutinação nas palavras que começam com o elemento "co-". Por essa razão, o Vocabulário Ortográfico da Língua Portuguesa, editado pela ABL, registra as palavras "coerdeiro" e "colegatário", motivo pelo qual ambas são adotadas pelo presente trabalho. Destaque-se ainda que o Código Civil atualmente em vigor foi sancionado no ano de 2002, portanto anteriormente às referidas modificações na gramática da língua portuguesa.
} 
mesma porção da herança, sem quotas determinadas. Além disso, o direito de algum dos instituídos deve ter caducado. Ambas as circunstâncias devem ser explicadas de forma aprofundada.

\subsubsection{DISPOSIÇÕES CONJUNTAS}

Para a constituição do direito de acrescer, é necessário que a liberalidade testamentária tenha sido destinada conjuntamente a duas ou mais pessoas, tendo por objeto a mesma coisa ou a mesma parte ideal da herança, sem especificação do quinhão que competirá a cada sucessor. A disposição conjunta "é aquela em que vários herdeiros, ou legatários, são chamados, coletivamente, para a fruição dos bens do testador, ou de uma certa porção deles" (ITABAIANA DE OLIVEIRA, 1952, p.503).

A respeito do direito de acrescer entre colegatários, o artigo 1.942 do Código Civil de 2002 determina apenas que ele será verificado quando faltar um dos sucessores nomeados conjuntamente sobre a mesma coisa determinada e certa ou que não possa ser dividida sem se desvalorizar. Note-se que o legislador estabeleceu um requisito adicional para o ius accrescendi na sucessão a título singular, em relação à sucessão a título universal.

De fato, prevê-se uma limitação ao mencionado fenômeno, restringindo-o a legados que tiverem por objeto coisa infungível, específica, individualizada, ou cuja divisão possa acarretar a sua desvalorização. Trata-se de exigência que não havia no Direito Romano, implementada apenas com o Código de Napoleão (NONATO, 1957, v.III, p.226), sendo replicada pelos Códigos Civis brasileiros de 1916 e de 2002.

Na medida em que o mencionado artigo 1.942 somente faz referência a legatários nomeados conjuntamente, conclui-se que, nesta hipótese específica, admite-se o ius accrescendi tanto quando houver disposições conjuntas re tantum quanto re et verbis. Desse modo, "os legatários podem receber a mesma coisa, no mesmo testamento, mas em disposições diferentes" (VENOSA, 2011, p.295).

Perceba-se que não há direito de acrescer quando dois ou mais herdeiros ou legatários são chamados através de conjunção verbis tantum. Nesta modalidade de disposição conjunta, o testador especifica e determina o quinhão que competirá a cada sucessor, motivo pelo qual não se justifica o acréscimo da parte daquele que eventualmente vier a faltar na sucessão. 


\subsubsection{A FALTA DE UM DOS COERDEIROS OU COLEGATÁRIOS}

Conforme supra estabelecido, além do chamamento conjunto dos coerdeiros ou dos colegatários, é necessário que o direito de um destes sucessores venha a caducar para que se opere o ius accrescendi. Ocorre tal caducidade da vocação sucessória quando falta o chamado à sucessão, por impossibilidade ou recusa em aceitá-la.

O já mencionado e transcrito artigo 1.943 do Código Civil estabelece que, faltando um dos coerdeiros ou colegatários, a sua parte acrescerá ao quinhão dos demais sucessores. O mesmo dispositivo estabelece que faltará o sucessor, por não poder aceitar a liberalidade testamentária, quando este morrer antes do de cujus, quando for excluído da sucessão ou quando não se verificar a condição sob a qual fora instituído. Por outro lado, o sucessor também poderá faltar por não querer aceitar a herança ou o legado, hipótese em que se verifica a renúncia.

O Código Civil não fala em ius accrescendi quando há comoriência entre o sucessor e o sucedido, todavia a doutrina se posiciona no sentido de que "a conclusão é a mesma, ocorrendo o direito de acrescer, pois que desaparece o sujeito quando da aquisição do direito" (VENOSA, 2011, p.294). Idêntica orientação é corroborada por Luiz da Cunha Gonçalves (1962, p.39) e Orosimbo Nonato (1957, v.III, p.237).

Se o coerdeiro ou colegatário vier a falecer após a abertura da sucessão, inexiste o direito de acrescer em um primeiro momento, na medida em que o benefício testamentário já foi incorporado ao seu patrimônio. A faculdade de deliberar a respeito da aceitação ou renúncia à herança ou ao legado é transmitida aos seus próprios herdeiros. Somente na hipótese destes últimos renunciarem ao quinhão que lhes é de direito, verificar-se-á o acréscimo em benefício dos demais coerdeiros ou colegatários.

Apesar do silêncio legal, também se justifica a ocorrência do direito de acrescer na hipótese de um dos coerdeiros ou colegatários não poder aceitar a herança ou o legado emrazão de falta de legitimação para suceder ${ }^{6}$. Neste caso, a disposição testamentária em favor do não legitimado será nula, porém esta invalidade não contaminará a deixa em favor dos demais beneficiados (VENOSA, 2011, p.294).

Em qualquer caso, o Código Civil ressalva o direito do substituto. O legislador confere ao disponente uma amplitude tão grande no exercício da autonomia privada quanto à sua última vontade, que é permitido ao testador instituir não apenas um sucessor em primeiro 
grau, mas também lhes indicar substituto, o qual receberá a liberalidade na falta do herdeiro ou legatário nomeados" (GONÇALVES, C., 2013, p.400). Dessa forma, não haverá direito de acrescer se o testador tiver instituído substituição, na medida em que o substituto vem à sucessão ocupar o lugar do sucessor faltante, tomando para si o quinhão que a este pertenceria.

\subsubsection{OS EFEITOS DO DIREITO DE ACRESCER}

Verificadas concomitantemente as condições acima expostas, o direito de acrescer se opera de pleno direito. O acréscimo é tido como forçado, não sendo em regra facultado ao sucessor aceitar o quinhão originário e repudiar a parte acrescida, decorrente da falta de um coerdeiro ou colegatário. Esta regra é excepcionada na hipótese de o quinhão do sucessor faltante comportar encargos especiais impostos pelo testador, hipótese na qual o coerdeiro ou colegatário poderá repudiar o acréscimo, que será revertido para a pessoa a favor de quem os encargos foram instituídos ${ }^{7}$.

Luiz da Cunha Gonçalves (1962, p.42) assevera que o ius accrescendi não é uma transmissão, pois o indivíduo faltante não chegou a adquirir a herança ou o legado. Os demais sucessores adquirem os respectivos quinhões como se o testador não tivesse beneficiado aquele que não pôde ou não quis aceitar o benefício testamentário. O mencionado autor conclui, em decorrência disto, que "o imposto de sucessão terá de ser só um: o liquidado em relação à herança do testador”.

Os beneficiados pelo ius accrescendi ficam sujeitos às obrigações ou encargos que oneravam o quinhão que se lhes acresceu, em observância ao princípio portio portioni adcrescit, non personae (GONÇALVES, C., 2013, p.396). A mesma conclusão alcança Orosimbo Nonato (1957, v.III, p.237), ao aduzir que "onde estão os cômodos cabem os ônus respectivos", e que o descumprimento dos mencionados ônus seria "um desrespeito à vontade do testador".

\footnotetext{
${ }^{6}$ Hipóteses do artigo 1.801 do Código Civil.

${ }^{7}$ Trata-se de norma estabelecida no artigo 1.945 do Código Civil de 2002. O referido diploma, porém, não estabelece a solução para a hipótese de o encargo sobre a deixa testamentária ter sido instituído em favor da coletividade.
} 
Por força do artigo 1.793 do Código Civil, o direito à sucessão aberta e o quinhão de que disponha o sucessor podem ser cedidos, desde que por instrumento público. Realizada a cessão de tais direitos, e sobrevindo o ius accrescendi, o respectivo acréscimo é presumido como não abrangido pelo mencionado negócio jurídico.

De acordo com Carlos Maximiliano (1964, p.479), “a vontade não se aplica ao desconhecido - non fertur ad incognita; por isso, vendido, ou cedido, legado ou herança, a parte acrescida cabe, em regra, ao vendedor, ou cedente; não ao comprador, ou cessionário". Ressalva-se, todavia, a possibilidade de previsão em sentido contrário pelos contratantes. Conforme ensina Silvio Venosa:

Parece mais de acordo com a vontade presumida do testador que, se o cedente não tinha conhecimento do acréscimo, transferiu somente sua porção originária, mesmo porque sua intenção de alienação poderia não existir, se soubesse do acréscimo, e o preço pedido deveria ser maior. Importa examinar o que ficou estampado na cessão. No silêncio, o direito de acrescer beneficia o herdeiro, não beneficiando automaticamente um terceiro. (VENOSA, 2011, p.294)

Quando não se verificar o direito de acrescer entre coerdeiros, a quota vaga será partilhada na conformidade da sucessão legítima. Quando não se operar o ius accrescendi entre colegatários, o quinhão do que faltar acresce ao herdeiro ou ao legatário incumbido de satisfazer esse legado - ou a todos os herdeiros, na proporção dos seus quinhões, se o legado se deduziu da herança.

\section{O DIREITO DE ACRESCER NO LEGADO DE DINHEIRO}

Até este momento, foram analisados os aspectos pertinentes ao instituto dos legados, especificamente a disposição testamentária que beneficia o legatário com uma determinada quantia em dinheiro. Foram expostos os requisitos para que se opere o direito de acrescer entre sucessores testamentários, bem como os efeitos de tal fenômeno.

Demonstrou-se, assim, que o Código Civil brasileiro exige, para a configuração do ius accrescendi, além da falta de um dos colegatários, que os sucessores a título singular tenham sido chamados conjuntamente sobre uma mesma coisa certa e determinada ou que não 
se possa dividir sem risco de desvalorização. Por outro lado, verificou-se também que o dinheiro é bem essencialmente fungível, na medida em que a relevância jurídica da moeda está em seu valor econômico.

Por força de consequência, a doutrina é firme no posicionamento de que o direito de acrescer não vinga na eventual falta um dos beneficiados com o legado de dinheiro, visto que o objeto da sucessão seria, neste tocante, bem genérico e divisível (MAXIMILIANO, 1964, p.473). Silvio Rodrigues (2003, p.226) afirma que, ainda que a disposição testamentária seja re et verbis, a fungibilidade do dinheiro o exclui do ius accrescendi. No mesmo sentido entende Sebastião Luiz Amorim:

No legado em dinheiro, não há possibilidade de acrescer, visto que o artigo 1.942 do Código Civil é bem claro quando estabelece que esse direito só tem cabimento nos legados que tenham por objeto coisa certa e determinada. Em se tratando de coisa genérica fungível, excluído é o direito de acrescer nos legados em dinheiro. (AMORIM, 2004, p.229)

Apesar da coerência argumentativa dos referidos doutrinadores, há uma circunstância específica apresentada pela presente pesquisa que demanda uma maior reflexão, antes de se concluir pela total impossibilidade de direito de acrescer no legado de dinheiro.

Conforme já constatado, o legado de dinheiro pode se apresentar de três maneiras distintas. O testador pode indicar um valor nominal genérico a ser entregue ao beneficiário; pode destinar uma quantia-paradigma em ativos financeiros, a ser pago ao sucessor em moeda nacional; ou pode ainda destinar ao legatário uma soma pecuniária localizada em um lugar específico. É esta última situação que chama a atenção para o problema que ora é investigado.

Imagine-se que o testador tenha elaborado cláusula prevendo disposição semelhante a "deixo a $C$ vinte mil reais que se encontram no cofre de minha residência". Consoante o que já se asseverou, neste cenário, entrega-se ao legatário o montante existente no local especificamente indicado, evidentemente até o valor previsto na deixa.

Esta hipótese corresponde a uma conjunção do instituto do legado de dinheiro com o legado de coisa localizada, este previsto no artigo 1.917 do Código Civil. Afinal, trata-se de uma quantia pecuniária que deve ser encontrada em determinado lugar. 
As diretrizes do testador, nesta circunstância específica, não estão limitadas a determinar a quantidade de dinheiro, fungível por essência - a vontade testamentada vinculase também a lugar certo e inconfundível. Mais do que determinado, o montante pecuniário é individualizado pelo testamento.

De fato, por expressa previsão legal, o legado somente terá eficácia se o bem for encontrado especificamente no lugar indicado, ressalvada a remoção do objeto a título transitório. Percebe-se então que não há qualquer possibilidade de que o objeto do legado seja confundido com outro de mesmo gênero.

É por essa razão que, individualizado o local onde deverá ser encontrado o dinheiro legado, se lá houver menos do que o indicado, nenhum direito possui o legatário de requerer que o restante da herança arque com a diferença faltante. Considera-se, em tais circunstâncias, não apenas o valor nominal da deixa, mas principalmente a sua localização. Assim, verifica-se a infungibilidade nesta modalidade específica de legado de dinheiro.

Admitindo-se o caráter infungível do dinheiro quando irreversivelmente vinculado, pelo legador, a um local específico, constitui consectário lógico a possibilidade de exercício do direito de acrescer. Assim, em observância ao ius accrescendi, havendo instituição de dois ou mais legatários sobre a mesma soma em dinheiro cuja localização foi especificada, a falta ou recusa de um dos colegatários implicará o acréscimo de sua parcela ao quinhão dos demais.

\section{CONCLUSÃO}

O presente trabalho buscou analisar a hipótese de que não é aplicável o direito de acrescer ao legado de dinheiro. Inicialmente, realizou-se uma análise conceitual da mencionada disposição testamentária. Em seguida, aprofundou-se no estudo do fenômeno em relação ao ius accrescendi.

$\mathrm{Na}$ análise a respeito da sucessão a título singular, expôs-se que o legado de dinheiro é, a priori, marcado pela fungibilidade. Todavia, o mencionado benefício testamentário pode ser instituído de diferentes modos. Uma dessas modalidades é a situação na qual o de cujus contempla o legatário com um montante a ser encontrado em local especificamente determinado. Neste caso, peculiarmente se verifica que o objeto de tal legado é infungível. 
Em realação ao direito de acrescer entre colegatários, demonstrou-se que o direito positivo brasileiro o restringe à hipótese de estes sucessores terem sido instituídos sobre a mesma coisa certa e determinada ou cuja divisão gere risco de desvalorização. Assim, não há ius accrescendi quando o legado consistir em coisa fungível.

Por tudo quanto foi exposto, conclui-se que, em princípio, a hipótese suscitada pode ser confirmada, no sentido de, em regra, não haver direito de acrescer em se tratando de legado de dinheiro, pois incompatível o ius accrescendi com a fungibilidade deste benefício testamentário. Excepcionalmente, entretanto, admite-se o acréscimo em se tratando da modalidade específica de legado na qual o testador especifica o local onde a quantia deverá ser encontrada para ser entregue aos sucessores, e um destes vem a faltar.

\section{REFERÊNCIAS}

AMARAL, Francisco. Direito civil: introdução. - 7. ed. rev., atual. e aum. - Rio de Janeiro: Renovar, 2008.

AMORIM, Sebastião Luiz. Código Civil Comentado: direito das sucessões, sucessão testamentária: Artigos 1.857 a 1.990, Volume XIX. São Paulo: Atlas, 2004.

BEVILAQUA, Clovis. Direito das successões. Segunda edição, revista e accrescentada. Rio de Janeiro: Livraria Editora Freitas Bastos, 1932.

DANTAS, San Tiago. Direitos de família e das sucessões. Rio de Janeiro: Forense, 1991.

GONÇALVES, Carlos Roberto. Direito Civil Brasileiro, volume 7: direito das sucessões. 7. ed. - São Paulo: Saraiva, 2013.

GONÇALVES, Luiz da Cunha. Tratado de direito civil, em comentário ao Código Civil Português. $2^{\mathrm{a}}$ Edição atualizada e aumentada e $1^{\mathrm{a}}$ Edição brasileira. Adaptação do direito brasileiro completada sob a supervisão dos Ministros Orozimbo Nonato, Laudo de Camargo e Prof. Vicente Ráo. Volume X, Tomo I. São Paulo: Max Limonad, 1962.

HIRONAKA, Giselda Maria Fernandes Novaes. Morrer e suceder: passado e presente da transmissão sucessória concorrente. 2. ed. rev. São Paulo: Editora Revista dos Tribunais, 2014.

ITABAIANA DE OLIVEIRA, Arthur Vasco. Tratado de Direito das Successões, Vol II . 3. ed. - Rio De Janeiro: Livraria Jacintho, 1936.

Tratado de Direito das Sucessões, vol. II: da sucessão testamentária. $4^{\text {a }}$ edição revista e atualizada pelo autor com a colaboração de Aires Itabaiana de Oliveira. São Paulo: Max Limonad, 1952. 
Curso de Direito das Sucessões. 2. ed. Rio de Janeiro: Editorial Andes, 1954.

LACERDA DE ALMEIDA, Francisco de Paula. Successões. Rio de Janeiro: Revista dos Tribunais, 1915.

MAXIMILIANO, Carlos. Direito das Sucessões, v. I. $3^{\text {a }}$ Ed. Rio de Janeiro: Freitas Bastos, 1952.

1964.

Direito das Sucessões, volume II. 5. ed. - Rio de Janeiro: Livraria Freitas Bastos,

NONATO, Orosimbo. Estudos sobre Sucessão Testamentária, volume I. Rio de Janeiro: Revista Forense, 1957.

Estudos sobre Sucessão Testamentária, volume II. Rio de Janeiro: Revista Forense, 1957.

Estudos sobre Sucessão Testamentária, volume III. Rio de Janeiro: Revista Forense, 1957.

OLIVEIRA, Euclides de. Formas de testamento. In: TARTUCE, Flavio; CASTILHO, Ricardo (org.). Direito civil: direito patrimonial e direito existencial. Estudo em homenagem à professora Giselda Maria Fernandes Novaes Hironaka. São Paulo: Editora Método, 2006.

PEREIRA, Antônio. Co-herdeiro ou coerdeiro? 2013. Disponível em: < http://acordoortografico.blogspot.com.br/2013/05/co-herdeiro-ou-coerdeiro.html>. Acesso em 30 de março de 2016.

PEREIRA, Caio Mário da Silva. Instituições de direito civil, v.6. Rio de Janeiro, Editora Forense, 2006.

PONTES DE MIRANDA, Francisco Cavalcanti. Tratado dos testamentos, v.3. Leme: BH Editora e distribuidora, 2005.

RIBEIRO, Raphael Rego Borges. Elementos de teoria da interpretação do direito e sua aplicação aos testamentos. In: Anais do XXIV CONGRESSO NACIONAL DO CONPEDI Hermenêutica jurídica [Recurso eletrônico on-line] organização CONPEDI/ UFMG/FUMEC/ Dom Helder Câmara; coordenadores: Enoque Feitosa Sobreira Filho, Rubens Beçak, Rodolfo Viana Pereira - Florianópolis: CONPEDI, 2015. Disponível em:

<http://www.conpedi.org.br/publicacoes/66fs1345/mxxdexv2/gCtgXS3u77Yf532m.pdf>. Acesso em 28 de março de 2016.

RIZZARDO, Arnaldo. Direito das sucessões. 6. ed. - Rio de Janeiro: Forense, 2011.

RODRIGUES, Silvio. Direito civil: direito das sucessões, volume 7. 26. ed. rev. e atual por Zeno Veloso, de acordo com o novo Código Civil. São Paulo: Saraiva, 2003.

TELLES, Inocêncio Galvão. Apontamentos para a história do direito das sucessões português. Lisboa: Universitas Olisponensis, 1963. 
VELOSO, Zeno. Testamentos - noções gerais; formas ordinárias; codicilo; formas especiais. In: HIRONAKA, Giselda Maria Fernandes Novaes; PEREIRA, Rodrigo da Cunha (coord.) Direito das sucessões e o Novo Código Civil. Belo Horizonte: Del Rey, 2004.

VENOSA, Silvio de Salvo. Direito civil: direito das sucessões. 11. ed. São Paulo: Atlas, 2011. 